\title{
How do Users Respond to Technostress? An Empirical Analysis of Proactive and Reactive Coping
}

\author{
Christoph Weinert \\ University of Bamberg \\ christoph.weinert@uni- \\ bamberg.de
}

\author{
Maier Christian \\ University of Bamberg \\ christian.maier@uni- \\ bamberg.de
}

\author{
Sven Laumer \\ Friedrich-Alexander \\ University Erlangen-Nürnberg \\ sven.laumer@fau.de
}

\author{
Tim Weitzel \\ University of Bamberg \\ tim.weitzel@uni- \\ bamberg.de
}

\begin{abstract}
As technostress costs organizations financial resources and threatens the well-being, it is essential for users as well as companies to manage technostress. To do so, users cope proactive by removing or reducing techno-stressors or reactive by restoring users' emotional state. However, literature is limited by explaining what factors lead to proactive and reactive coping in a short-term technostress situation. The present paper addresses these shortcomings by investigating in how techno-stressors and emotional exhaustion influences proactive and reactive coping. Results based on 110 users show that users respond to techno-stressors in a proactive way, whereas users reactively respond to emotional exhaustion. In addition, proactive coping is stronger affected by technostressors, and reactive coping is stronger affected by emotional exhaustion. Thereby, we contribute to technostress and coping literature by demonstrating how users respond in short-term technostress situation and highlight the importance of time in the present context.
\end{abstract}

\section{Introduction}

Imagine the following exemplary situation. John Doe, a 45-year-old key account manager, who works in an international company, which has recently implemented a new enterprise content management system (ERP). John uses the ERP system day in day out and evaluates the usage of the ERP system as complex. This causes feelings of exhausted. Thus, John perceives the complexity of the ERP system as a threat and exhaustion as a consequence while using the ERP system. He might respond to the cause and the consequences in the current situation in different ways. It might be that John responds to the complexity by proactively doing something against it, whereas John responds towards the consequence in terms of the feelings of exhaustion by disengage from the ERP system by playing Tetris.
From a theoretical perspective, the use of an information system (IS) leads to situations in which users encounter techno-stressors encompassing, for example, IS complexity that results in negative consequences such as feelings of emotional exhaustion [43]. As technostress costs organizations financial resources, risking the investments of organizations in implementing new IS and threatens the well-being of users [42] it is essential for users as well as companies to manage technostress. To do so, users appraise the situation and subsequently cope in response to technostress [22, 32]. Literature indicates that users proactively cope by removing or reducing technostressors or reactively by restoring the users' emotional state back to normal $[20,36]$.

However, literature neglects how users respond towards techno-stressors and emotional exhaustion. For instance, in medicine, doctors evaluate the causes and the consequences of illness and decide to treat the cause or the consequences depending on the type of the illness (e.g., bacterial or virus infection) and hence prescribe a different medication to manage the illness, because cause and consequences need different treatments. Hence, technostress literature is limited by explaining how users respond in terms of proactive and reactive coping to techno-stressors and emotional exhaustion. As technostress is a serious issue for users and organizations, the present paper addresses these shortcomings by investigating in what way users respond in terms of proactive and reactive coping to the techno-stressors and emotional exhaustion. Therefore, the present research aims to answer the research question:

How do techno-stressors and techno-exhaustion influence proactive and reactive coping?

To respond to that research question, coping theory [22] and technostress [43] guides our research. Technostress includes causes such as techno-stressors and consequences such as emotional exhaustion. Thereby, we theorize that users respond differently to techno-stressors and emotional exhaustion. Our results 
show that the perception of techno-stressors lead to proactive coping and feelings of emotional exhaustion leads to reactive coping. We also reveal that technostressors stronger affects reactive coping, whereas emotional exhaustion stronger affects proactive coping.

To outline and explain the contribution of this research, the remainder of this paper is as follows. In the theoretical background section, we explain the transactional process of technostress, coping theory, types of coping in the domain of technostress and outline the past literature concerning coping. Afterward, we develop the research model and present the methodology and research results. Finally, the theoretical and practical contributions, as well as limitations and future research directions are outlined.

\section{Theoretical background}

In this section, we first explain technostress, as this is one domain in which coping theory has been applied in IS research. Then, we focus on coping theory and demonstrate the types of coping in relation to technostress. Finally, prior IS coping literature is discussed.

\subsection{Technostress}

Technostress is defined as stress perceived when using IS [34]. Technostress result when there is an imbalance between users and their environment [7]. The imbalance results when the values and abilities or the supplies and demands of the environment do not meet [2]. When the demands of the environment exceed the individual's abilities, the balance between users and their environment is disrupted such that the demands may be perceived as unpleasant $[38,41]$.

Technostress is understood as a transactional process overarching causes and their consequences [43]. Causes are techno-stressors (i.e., work overload, role ambiguity, invasion of privacy, job insecurity, and work-home conflict), which are technology-related stimuli resulting in negative consequences [2, 25, 43]. Negative consequences are strains that can be psychologically in terms of emotional exhaustion which is understood as emotional reactions to the encountered stimuli $[2,25]$. Emotional exhaustion is the feeling of tension and depletion of one's emotional resources [29, 30].

\subsection{Coping}

2.2.1. Coping theory. To understand the responses towards technostress, research has used the lens of coping theory. Coping is a function of behavioral, cognitional, and perceptual efforts to handle threatening situations [22, 31].

Coping theory states that users go through a cognitive appraisal process containing primary appraisal, during which users evaluate the potential negative consequences of being threatened by the demands and secondary appraisal, during which users evaluate their ability to handle the perceived demands [22].

Based on the cognitive appraisal process each user selects a coping strategy, which contains behavioral and cognitive efforts to handle the demand. Numerous coping strategies exist [37], which either aim to manage the problem or handle the resulting emotions. Problemfocused coping (PFC) aims to mitigate the problem and determine the direct problem such as by active coping or instrumental support. Emotion-focused coping (EFC) aims to regulate emotions tied to the demand by trying to change them to, e.g., acceptance and positive reinterpretation [21].

2.2.2. Proactive and reactive coping. Coping literature indicates that users might cope with technostress differently such that they try to cope with the cause (e.g., techno-stressors) and with the consequences themselves (e.g., emotional exhaustion) [20, 36]. IS coping literature suggests that different types exist how users cope with technostress [36], whereby each coping type encompasses different coping strategies.

One type, the proactive coping, focuses on the direct problem and prevent direct exposure to techno-stressors by removing or reducing them. Users actively cope with techno-stressors by modifying the IT features [20, 36]. For example, users might proactively change or disable the settings of notifications, which they perceived as a threat to cope proactive with the cause (e.g., technostressors).

The second type, reactive coping, aims at restoring the users' strained emotional state back to normal but does not address the original techno-stressor. If users could not reduce techno-stressors or build tolerance to them, they still are able to mitigate technostress temporarily by minimizing the level of their exhaustion $[20,36]$. For example, users trying not to think about the issue by disengage from it by doing other activates.

In sum, coping is a function of behavioral, cognitional, and perceptual efforts to handle threatening demands. Two main categories of coping strategies exist, namely PFC and EFC. Moreover, beyond the categories of coping strategies IS coping literature 
indicate that users proactively or reactively cope. However, literature neglects what factors evoke such different coping types in a short-term technostress situation.

\subsection{Related work on coping and technostress}

Several investigations focus on coping in the domain of technostress (see [45] for a more detailed review). Some investigations focus on the effect of coping strategies on the relationship between cause and consequences. For example, Galluch et al. [16] show that the performance of coping strategies in terms of method and resource control moderate the relationship between techno-stressors and strain responses. A recent investigation examines whether emotion-focused coping strategies such as distress, venting and distancing from IT moderates the relation between techno-stressors and strain. In addition, they investigated the role of IT control in this context. Results showed that distress venting reduces the effect of techno-stressors on strain but only when users have low IT control. Furthermore, they revealed that distress venting has a direct positive effect on strain such that the higher distress venting the higher strain [32]. Srivastava et al. [38] suggest that the effect of techno-stressors on job burnout, as well as on job engagement, is moderated by dominant personality traits such as openness-toexperience, neuroticism, agreeableness, conscientiousness, and extraversion. The findings showed that personality traits have increasing and decreasing effects on the relationship between technostressors and their consequences.

Moreover, D'Arcy et al. [13] show that coping strategies such as moral disengagement mediate the relationship between security-related stressors and the intention to violate the information security policy of an organization and thereby influences the consequences directly. Another investigation examined whether coping influences anxiety, stress, and depression among IT personnel. Five different coping strategies were studied: social support, active coping, cognitive avoidance coping, self-controlling coping, and accepting responsibility coping. The findings indicated that active coping had no significant effect on anxiety, stress, and depression, whereas all other coping strategies positively affected these the consequences in terms of anxiety, strain, and depression [24].

None of the investigations focused on the effect of coping strategies on the cause such as techno-stressors. Moreover, another examination shows that users cope with technostress and switching-stress by stopping using the IS entirely [26] and hence only investigate the antecedents of coping strategies and neglect its effect.
Based on the literature above, we conclude that IS coping research mostly examines the effect of coping on technostress and neglects the investigation in what way users respond when perceiving technostress in a shortterm technostress situation. Consequently, current literature does not reveal which factor triggers proactive and which factor causes reactively coping. To close this research gap and to shed more light on how technostressors and emotional exhaustion lead to proactive and reactive coping, we develop in the following a research model that assumes that users respond to techno-stressor in a proactive way, whereas they reactively respond to emotional exhaustion in a short-term technostress situation. Although several proactive and reactive coping strategies exist, we focus on active coping as proactive coping strategies and mental disengagement as reactive coping strategies.

\section{Hypothesis development}

In the following section, we develop our research model. However, previous technostress and coping literature (e.g., [4, 41]) does not consider the effect of time, whereas coping strategies need time to reduce causes or consequences (e.g., pre-coping vs. postcoping). Thereby, we focus on a short-term technostress situation (one-time consideration) where a user perceives techno-stressors and the following feelings of emotional exhaustion and immediately respond in terms of proactive and reactive coping. The subsequent mitigation effects of coping such as regulation of negative outcomes [41] or the minimization of the negative consequences of the techno-stressors [4], which occur over time (effect of pre-coping vs. postcoping) are thereby neglected (see Figure 1).

Previous technostress research reveals that technostressors in terms of work-home conflict, invasion of privacy, work overload, role ambiguity, and job insecurity and lead to techno-exhaustion which is understood as the depletion of mental resources due to IT $[2,26]$. In general, the relationship between technostressors and emotional exhaustion is well-researched in the literature $[1,30,46]$. The perception of technostressors costs users' mental resources, which lead to on the one side to tiredness and fatigue reflecting technoexhaustion. Hence, we assume in line with past literature that:

H1: The higher the perception of techno-stressors, the higher emotional exhaustion.

Coping theory indicates that individuals respond to stressful situations by managing or mitigating the circumstances [14]. In particular, extend previous IS coping literature indicate that the perception of technostressors lead to a coping response to deal with them [4, 
13, 41]. For example, the coping model of user adaptation (CMUA) claims that threatening stimuli (e.g., techno-stressors) lead to coping responses and Tarafdar et al. 2017 [41] demonstrate that coping responses following on techno-stressors. Moreover, psychological research indicates that users primarily respond proactively [20] by actively modifying or doing something against it. Users focus on the direct problem and prevent direct exposure to techno-stressors by trying to remove or reduce them [36]. For example, users respond with actions to deal with threats [41]. Salo et al. [36] report, for example, that users disable notifications settings in response to threatening popups. This indicates that users with high perceptions of technostressors respond in high proactive coping. Remember John; he perceives the complexity of the ERP system and immediate respond with proactive coping by performing efforts to reduce such complexity. Hence, we assume that:

H2a: The higher the perception of the techno-stressors, the higher proactive coping.

We assume that users receiving emotional exhaustion respond in terms of reactive coping. Emotional exhaustion is the depletion of the emotional resources and results out of the perceptions of technostressors [25, 29, 30]. In addition, it is one specification of significant illnesses such as burnout [27, 28]. Moreover, the psychological literature indicates that users cope reactively [20]. This means that they aim to restore the emotional state back to normal but does not address the perception of techno-stressors. As emotional exhaustion represents one dimension of a serious illness, users might have a lower control over their emotional response such that they respond in a reactive way by performing EFC strategies which are preferably used, when the controllability is low [22]. If users have low control and cannot reduce techno-stressors or build a tolerance to them, they still are able to mitigate the level of their exhaustion [36].

Consequently, when users have a high emotional exhaustion level, they might respond in terms of reactive coping by disengaging. Remember John; he perceived the complexity of the ERP system and the thus resulting feelings of exhaustion. As he might appraise the situation with low controllability over his feelings, he immediately responded reactively by mentally disengage. Therefore, we assume that:

$\boldsymbol{H} 2 \boldsymbol{b}$ : The higher the emotional exhaustion, the higher reactive coping.

Regarding techno-stressors, we propose that the perception of techno-stressors leads to a stronger response of proactive coping than reactive coping. Users might believe they have more control over the techno- stressors such as complexity such that they are able to respond to this by looking in the manual or watching elearning tutorials. Emotions are more challenging to control as they arise when users have low controllability. For example, emotions such as sadness or frustration evoke when users have low controllability $[5,39]$. Coping literature indicates that the secondary appraisal (e.g., controllability) determines whether individuals respond either proactive by tackling the problem or reactive by disengaging from it [22]. In addition, as emotional exhaustion is associated with illnesses [27, 28], users with intense feelings of emotional exhaustion might be too tired to do something actively against the real problem and hence prefer to disengage. Remember John; he perceives the complexity of the ERP system and the thus resulting feelings of exhaustion. He might appraise the situation with more controllability over the techno-stressor than over the feelings of exhaustion such that the perceptions of techno-stressor have a stronger effect on proactive coping than emotional exhaustion. Hence, we assume that:

H3a: Techno-stressors have a stronger effect on proactive coping than emotional exhaustion.

Regarding emotional exhaustion, we suggest that the perception of emotional exhaustion leads to a stronger response of reactive coping than proactive coping. As mentioned above, users might have less controllability about their feelings [5, 39], which lead to reactive coping in terms of disengagement rather than proactive coping [22]. In addition, users might be too tired and exhausted to do something that they reactively disengage from the issue proactively. Remember John; he perceives the complexity of the ERP system and the thus resulting feelings of exhaustion. He might appraise the situation with less controllability over the feelings of exhaustion and feels too exhausted to do something about the issue that he reactively disengages. Hence, we assume that:

H3b: Emotional exhaustion has a stronger effect on reactive coping than techno-stressors. 


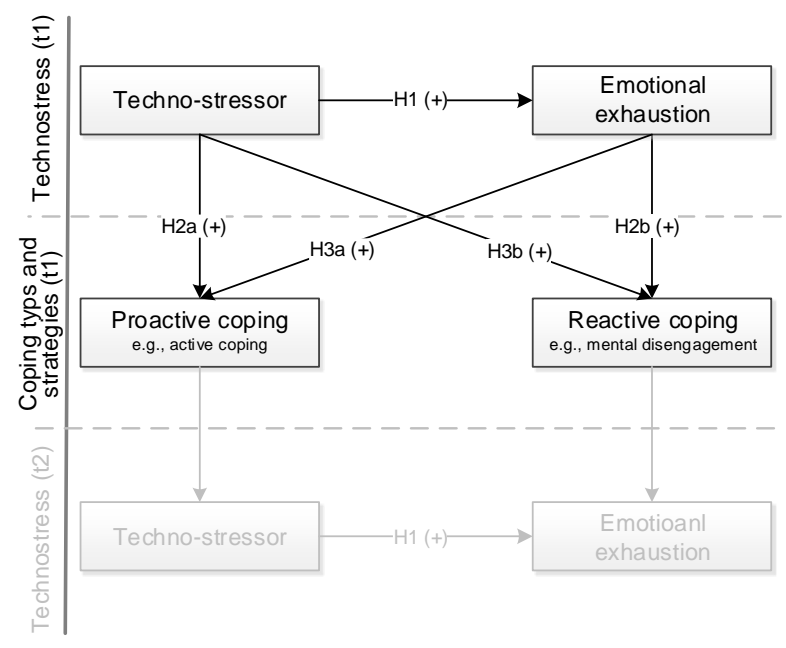

Figure 1. Research model

\section{Research methodology: design and measurement}

\begin{tabular}{|l|c|c|c|c|c|}
\hline \multicolumn{6}{|c|}{ Demographics (N=110) } \\
\hline \multicolumn{2}{|c|}{ Gender (\%) } & \multicolumn{2}{c|}{ Age (\%) } & \multicolumn{2}{c|}{ Educational status (\%) } \\
\hline Men & 47.7 & $15-24$ & 17.8 & $\begin{array}{c}\text { Lower secondary } \\
\text { education }\end{array}$ & 8.4 \\
\hline Women & 52.3 & $25-34$ & 59.4 & Secondary school & 24.3 \\
\hline & & $35-44$ & 8.9 & Higher school & 26.2 \\
\cline { 2 - 6 } & $45-54$ & 9.9 & Bachelor degree & 34.6 \\
\cline { 2 - 6 } & $55-64$ & 3.0 & Master degree & 6.5 \\
\cline { 2 - 6 } & $>65$ & 1.0 & \multicolumn{3}{|c}{} \\
\hline
\end{tabular}

Table 1. Study participants and their demographics

In this section, we describe our research design and the data collection process to validate the research model. We focus on the study procedure and present the measurement model used. To validate the research model, we captured data through an online survey. Following previous research [43], we captured data from employees of different organizations. We have established a database of employees working at different organizations with different sizes and out of different sectors, which we used to send a hyperlink to the questionnaire. The database contains around five hundred possible participants. In addition, the questionnaire has been distributed via several interest groups on Facebook and other social media platforms such as LinkedIn. In total, we received 194 responses and used the answers of 110 individuals as we must omit several answers because of a too high missing value rate. The sample reflects a suitable data set for our research as the majority of the sample are workers and uses IT. The demographics of the participants are demonstrated in Table 1. Because negative perceptions such as emotional exhaustion might cause skewed distributions
[44]; and since partial least square (PLS) does not require normally distributed data (compared to covariance-based structural equation modeling), we use structural equation modeling (SEM) in terms of SmartPLS 3.2.6 [35].

\section{Research Results}

Before we analyzed the results, we made sure that the research model is valid and reliable. Afterward, we present the research results.

\subsection{Validity and reliability}

Regarding the validity and reliability we follow well known guidelines [40].

Perceived and subjective measures are used to capture users' responses to a given situation. A potential issue with subjective measures is common method bias [33]. To evaluate the extent of CMB, we utilized Harman's single factor test [17] and the procedure suggested by Williams et al. [47]. The results of the Harman's single factor test showed that one factor explained $32.7 \%$ of the variance, which is not the majority, such that we concluded that CMB is of no great concern. Furthermore, we follow the procedure suggested by Williams et al. [47], during which an additional factor is entered into the PLS model, which contains each indicator of the original model. The remaining factors are transformed into single-item constructs, and the ratio of $\mathrm{R}^{2}$ with the $\mathrm{CMB}$ factor is compared with the $\mathrm{R}^{2}$ without the $\mathrm{CMB}$ factor. The CMB factor explains an average $\mathrm{R}^{2}$ of 0.027 so that a ratio of 1:362 is received. By comparing this ratio with the ratio of prior research using this approach [23], we can state that no signs of CMB influence are observed in consideration of the circumstances that this method is subjected to several flaws [11].

In addition, to provide a valid and reliable measurement model for testing our hypotheses, we first assessed the measurement model used. As all constructs were measured with reflective indicators, we validated the measurement model by focusing on content validity, indicator reliability, construct reliability, and discriminant validity [3].

Content validity: To ensure content validity, we used items that have been used in prior research articles and discussed each item within our project team. We measured techno-stressors and emotional exhaustion with the scales by Ayyagarie at al. 2011 [2], proactive coping in terms of active coping and reactive coping in terms of mental disengagement by the scales of Carver et al. 1989 [9]. All measurement items and their origins are presented in Appendix Table 3. 
Indicator reliability: This reflects the rate of the variance of an indicator that comes from the latent variables. To ensure that 50 percent or more of the variance is explained by the indicators, each value should be at least 0.707 [8]. All other items were removed from the model. Table 3 in the Appendix shows that this condition is fulfilled.

Construct reliability: To determine construct quality, we use composite reliability (CR), which should be at least 0.7 , and average variance extracted (AVE), which has to be at least 0.5 [15]. Both criteria were fulfilled (see Appendix Table 4). In addition, the Cronbach's Alpha values of all constructs were higher than 0.7 (see Appendix Table 3).

Discriminant validity: This reflects the extent to which items differ from others [6]. The square root of AVE should be greater than the corresponding construct correlations $[15,19]$. Table 4 shows that the square roots of the values were greater than the corresponding correlations between the constructs. We also ensure that the most conservative 0.85 heterotrait-monotrait (HTMT) criterion is fulfilled [18]. The highest correlation between techno-stressors and reactive coping is 0.54 - and hence lower than 0.85 - and the bootstrapping approach shows that HTMT is in each sample significantly different from one. Hence, we can state that discriminant validity is not an issue in the present research.

\subsection{Results}

Figure 2 shows the results of the structural model. The research model has been validated by the use of the significance levels of the path coefficients and the coefficient of determination $\left(\mathrm{R}^{2}\right)$ [10].

Generally, the results demonstrate that technostressors increase emotional exhaustion $(\beta=0.526$, $\mathrm{p}<0.005)$, which supports H1. In addition, technostressors are positively related with proactive coping in terms of active coping $(\beta=0.568, \mathrm{p}<0.005)$, which supports H2a. Regarding emotional exhaustion, the structural model demonstrates a positive relationship between emotional exhaustion and reactive coping in terms of mental disengagement $(\beta=0.291, p<0.01)$, which supports $\mathrm{H} 2 \mathrm{~b}$.

Moreover, our results support also $\mathrm{H} 3 \mathrm{a}$ and $\mathrm{H} 3 \mathrm{~b}$ as the results show only a significant effect of emotionalexhaustion on reactive coping, whereas the influence on proactive coping is insignificant $(\beta=-0.176, p>0.05)$. The influences of techno-stressors on proactive coping is significant, whereby we found no significant effect from techno-stressors to reactive coping $(\beta=0.189$, $\mathrm{p}>0.05)$. This is also indicated by the effect sizes $\left(\mathrm{f}^{2}\right)$ [12] shown in Table 2. The $\mathrm{f}^{2}$ values of techno-stressor on proactive coping is greater than on reactive coping.
In case of emotional exhaustion, it is the other way around, the $\mathrm{f}^{2}$ values are higher for reactive coping than for proactive coping.

Overall, the model explains $27.7 \%$ of the variance for emotional exhaustion, $25.2 \%$ of the variance of proactive coping in terms of active coping, and $18.4 \%$ of reactive coping in terms of mental disengagement.

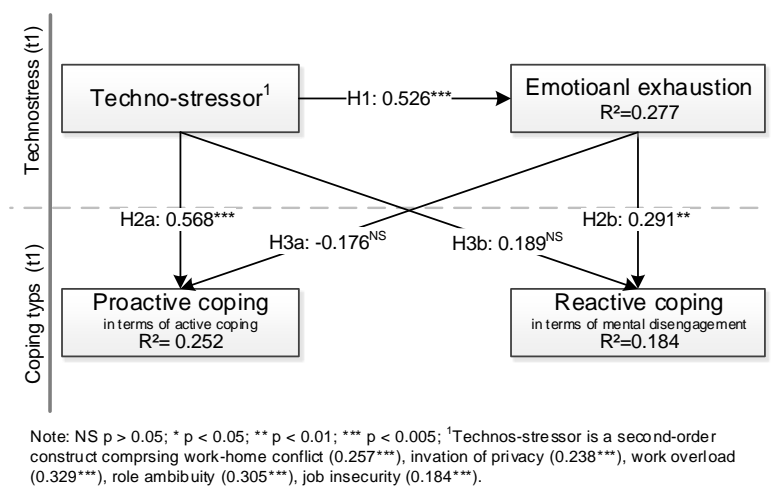

Figure 2. Structural model results

Table 2 shows that techno-stressor shows the most substantial effect on proactive coping and emotional exhaustion, whereas emotional exhaustion has the strongest effect on reactive coping.

\begin{tabular}{|c|c|c|}
\hline & Proactive coping & Reactive coping \\
\hline Emotional exhaustion & 0.03 & 0.08 \\
\hline Techno-stressor & 0.32 & 0.03 \\
\hline $\begin{array}{l}\text { Note: } f^{2} \text { means effect size; Cohen [12] interprets effect sizes as follows: } \\
>.35=\text { high effect; }>.15=\text { medium effect; }>.02=\text { low effect }\end{array}$ \\
\hline
\end{tabular}

Table 2. Effect sizes

\section{Discussion and Contributions}

We motivated our research with an example. We thereby show the relevance of technostress and its adverse consequences for the user. In detail, we argued that John Doe is struggling with the complexity of the IS which increases John's feelings of exhaustion. As John perceived on the one hand techno-stressors and on the other hand emotional exhaustion, he responds to techno-stressors and emotional exhaustion in a shortterm technostress situation in different ways. The present paper shows that John responds to technostressors with proactive coping tackling the real problem and respond to emotional exhaustion with reactive coping by disengagement from the issue. In addition, proactive coping is stronger influences by technostressors than by emotional exhaustion. Regarding reactive coping, the effect of emotional exhaustion is stronger than the effect of techno-stressors.

From a theoretical perspective, users encounter a cause in terms of techno-stressors, which lead to a 
consequence in terms of emotional exhaustion. As technostress depicts a threat to users and companies, it is essential for both to manage technostress. To do so, users cope with technostress. However, despite IS literature demonstrate that users encounter the causes and consequences of technostress and perform coping strategies, the literature is limited by explaining how users respond in terms of proactive and reactive coping to techno-stressors and to emotional exhaustion in shortterm technostress situations.

Therefore, we developed a research model that assumes that techno-stressors influences reactive coping and have a stronger effect on proactive coping than emotional exhaustion. Whereas, emotional exhaustion leads to reactive coping and has a stronger effect on reactive coping than techno-stressors. To validate the research model, we conducted an online survey. To test our hypotheses, we used an SEM approach. The main findings show that techno-stressors influence proactive coping and that the effect of techno-stressor is stronger than the effect of emotional exhaustion. Regarding emotional exhaustion, the results show that emotional exhaustion influences reactive coping and that emotional exhaustion has a stronger effect in reactive coping than techno-stressors. These results contain several contributions, which are explained in the following.

\subsection{Theoretical contributions}

The present research contains several theoretical contributions to technostress and coping literature, which are explained in the following.

\subsubsection{Contribution to technostress literature}

Technostress research demonstrates that technostressors lead to consequences such as exhaustion $[2,16$, 26] physiological arousal [16], or burnout [38]. The present examination extends previous technostress literature, which investigates the effect between technostressors, and its consequences by revealing that technostressor not only emphasize strains such as emotional exhaustion or physiological arousal but also coping responses in terms of proactive coping.

In sum, we show that techno-stressor not only lead to strains but also to reactive coping and extend the literature by indicating that emotional exhaustion leads to reactive coping. Hence, future technostress literature should consider that users might try to cope with technostressors, which has an effect on technostress over time.

\subsubsection{Contribution to coping literature}

The present research empirically demonstrates that users respond to techno-stressors by proactive coping and to emotional exhaustion by reactive coping. Thereby we contribute to coping literature in three different ways.

First, we contribute to IS coping literature [4, 41] by empirically showing that coping responses result from the perception of techno-stressor. For example, we extend the work by Beaudry and Pinsonneault 2005 [4], who propose that stimuli such as techno-stressors lead through different cognitive appraisal processes to coping strategies by empirically demonstrating that users who perceive techno-stressor respond with proactive coping in terms of active coping. In addition, we also extend the results by Tarafdar et al. 2017 [41] who suggest that coping responses follow technostressors by demonstrating the positive relationship between techno-stressor and proactive coping. In addition, we extend past coping literature claiming that coping strategies only results out of the perception of techno-stressors $[4,41]$ by demonstrate that emotional exhaustion leads to reactive coping in terms of disengagement.

Second, we contribute to literature investigating different coping types $[20,36]$ by empirically revealing different antecedents and hence show how these different coping types are triggered in short-term technostress situations. In particular, we extend the work by Salo et al. 2017 [36] and Lamontagne et al. 2007 [20] who examine different coping types (e.g., proactive coping, reactive coping) and suggest their effect on techno-stressors and outcomes by empirically investigating whether techno-stressor or emotional exhaustion influence each coping type. We reveal that techno-stressors influences proactive coping and have a stronger effect than emotional exhaustion. In addition, emotional exhaustion influences reactive coping and has a stronger effect on reactive coping than techno-stressor. Moreover, we reveal that techno-stressors also influence reactive coping.

Third, we deliberately examine a short-term technostress situation (one-time consideration) where a user perceives techno-stressors and the following feelings of emotional exhaustion and immediately respond in terms of proactive and reactive coping. We thereby, extend past coping literature (e.g., [4, 41]) which neglects time effect and assumes that the mitigation effects of coping such as regulation of adverse outcomes [41] or the minimization of the negative consequences of techno-stressors [4] appears immediately by demonstrating that techno-stressors and emotional exhaustion lead in a short-term technostress 
situation to coping. In addition, we propose that coping strategies only show its mitigation effect over time.

In sum, the present research empirically demonstrates that techno-stressor lead to proactive coping and emotional exhaustion to reactive coping. Thereby we contribute by (1) demonstrating that that coping responses result from the perception of technostressor, (2) showing that proactive and reactive coping have different antecedents, (3) deliberately examining a short-term technostress situation to investigate immediate coping responses, and by proposing that the mitigating effect of proactive and reactive coping occur over time. Hence, future coping literature should be aware that users respond differently to techno-stressors and exhaustion and should consider the time effects of coping as user show high coping responses in short-term technostress situation, which only reduces technostress over the long term.

\subsection{Practical contribution}

Technostress is a crucial issue for organizations. It costs organizations a significant amount of money because users might become exhausted and stop using the IS. Thus, the examination of coping efforts, which might reduce these costs, is highly relevant to practitioners. Based on our results the organizations should support the users perceiving high technostressors by proactive coping and users with high emotional exhaustion by reactively coping. Furthermore, organizations have to understand how users respond to technostress to measure its effects over time and to adjust the right screw to best support their employees.

\section{Limitations and Future Research}

The present examination is limited in several ways. Our research model concentrates on a general technostressor factor rather than treating different technostressors separately. Further, it contains only two coping strategies representing proactive and reactive coping, whereby numerous other exist. We captured technostressors, emotional exhaustion, proactive, and reactive coping at the same time point, which is suitable for the objective of the paper. However, future research should also consider the long-term effect of coping as only then the mitigation effect of coping might be revealed (e.g., comparison of pre-coping and post-coping).

\section{Conclusion}

The present paper investigates how users response in terms of proactive and reactive coping to techno- stressors and emotional exhaustion. Based on an online survey the present paper demonstrate that users proactively respond to techno-stressors, whereas users reactively respond to emotional exhaustion. In addition, the effects of techno-stressors on proactive coping is stronger than for emotional exhaustion, and for reactive coping, the effects are reversed. We conclude that it is necessary to understand how users respond to technostress and to realize the importance of time in the context of coping with technostress.

\section{References}

[1] Ahuja, M.K., K.M. Chudoba, C.J. Kacmar, D.H. McKnight, and J.F. George, "IT Road Warriors: Balancing Work-Family Conflict, Job Autonomy, And Work Overload to Mitigate Turnover Intentions", MIS Quarterly, 31(1), 2007, pp. 1-17.

[2] Ayyagari, R., V. Grover, and P. Russell, "Technostress: Technological Antecedents and Implications", MIS Quarterly, 35(4), 2011, pp. 831-858.

[3] Bagozzi, R.P., "The Role of Measurement in Theory Construction and Hypothesis Testing: Toward a Holistic Model", in Conceptual and theoretical developments in marketing, O.C. Ferrell, S.W. Brown, and C.W. Lamb, Editors. 1979. American Marketing Association: Chicago.

[4] Beaudry, A. and A. Pinsonneault, "Understanding user responses to information technology: a coping model of user adaptation", MIS Quarterly, 29(3), 2005, pp. 493-524.

[5] Beaudry, A. and A. Pinsonneault, "The Other Side Of Acceptance: Studying The Direct And Indirect Effects Of Emotions On Information Technology Use", MIS Quarterly, 34(4), 2010, p. 689.

[6] Campell, D.T. and D.W. Fiske, "Convergent and discriminant validation by the multitrait-multimethod matrix.", Psychological bulletin, 56(2), 1959, pp. 81-105.

[7] Caplan, R.D., "Person-environment fit theory and organizations: Commensurate dimensions, time perspectives, and mechanisms", Journal of Vocational behavior, 31(3), 1987, pp. 248-267.

[8] Carmines, E.G. and R.A. Zeller, Reliability and validity assessment, Sage, Newbury Park, Calif, 2008.

[9] Carver, C.S., M.F. Scheier, and J.K. Weintraub, "Assessing coping strategies: a theoretically based approach", Journal of personality and social psychology, 56(2), 1989, pp. 267-283.

[10] Chin, W.W., "The partial least squares approach for structural equation modeling.", in Modern methods for business research, G.A. Marcoulides, Editor. 1998. Lawrence Erlbaum.

[11] Chin, W.W., J.B. Thatcher, and R.T. Wright, "Assessing common method bias: problems with the ULMC technique", MIS Quarterly, 36(3), 2012, pp. 1003-1019. 
[12] Cohen, J., Statistical power analysis for the behavioral sciences, 2nd edn., L. Erlbaum Associates, Hillsdale, N.J, 1988.

[13] D'Arcy, J., T. Herath, and M.K. Shoss, "Understanding Employee Responses to Stressful Information Security Requirements: A Coping Perspective", Journal of Management Information Systems, 31(2), 2014, pp. 285318.

[14] Folkman, S., R.S. Lazarus, R.J. Gruen, and A. DeLongis, "Appraisal, coping, health status, and psychological symptoms", Journal of Personality and Social Psychology; Journal of Personality and Social Psychology, 50(3), 1986, pp. 571-579.

[15] Fornell, C. and D.F. Larcker, "Evaluating Structural Equation Models with Unobservable Variables and Measurement Error", Journal of Marketing Research, 18(1), 1981, pp. 39-50.

[16] Galluch, P.S., V. Grover, and J.B. Thatcher, "Interrupting the Workplace: Examining Stressors in an Information Technology Context", Journal of the Association for Information Systems, 16(1), 2015, pp. 1-47.

[17] Harman, H.H., Modern factor analysis, 3rd edn., University of Chicago Press, Chicago, 1976.

[18] Henseler, J., C.M. Ringle, and M. Sarstedt, "A new criterion for assessing discriminant validity in variance-based structural equation modeling", Journal of the Academy of Marketing Science, 43(1), 2015, pp. 115-135.

[19] Hulland, J., "Use Of Partial Least Squares (Pls) In Strategic Management Research: A Review Of Four Recent Studies", Strategic Management Journal, 20(2), 1999, pp. 195-204.

[20] Lamontagne, A.D., T. Keegel, A.M. Louie, A. Ostry, and P.A. Landsbergis, "A systematic review of the job-stress intervention evaluation literature, 1990-2005", International journal of occupational and environmental health, 13(3), 2007, pp. 268-280.

[21] Lazarus, R.S., "From Psychological Stress to the Emotions: A History of Changing Outlooks", Annual Review of Psychology, 44(1), 1993, pp. 1-22.

[22] Lazarus, R.S. and S. Folkman, Stress, appraisal, and coping, Springer Pub. Co., New York, 1984.

[23] Liang, H., N. Saraf, Q. Hu, and Y. Xue, "Assimilation of enterprise systems: the effect of institutional pressures and the mediating role of top management", MIS Quarterly, 31(1), 2007, pp. 59-87.

[24] Love, P.E.D., Z. Irani, and M. Themistocleous, "An Exploratory study of psychological adjustment and coping among information technology personnel in Australia", ECIS 2004 Proceedings, 2004, p. 77.

[25] Maier, C., S. Laumer, and A. Eckhardt, "Information technology as daily stressor: Pinning down the causes of burnout", Journal of Business Economics, 85(4), 2015, pp. 349-387.
[26] Maier, C., S. Laumer, C. Weinert, and T. Weitzel, "The effects of technostress and switching stress on discontinued use of social networking services: A study of Facebook use", Information Systems Journal, 25(3), 2015, pp. 275-308.

[27] Maslach, C., "Burnout: A multidimensional perspective", in Professional burnout: Recent developments in theory and research, W. B. Schaufeli, C. Maslach, and T. Marek, Editors. 1993. Taylor \& Francis: Philadelphia, PA, US.

[28] Maslach, C. and S.E. Jackson, "The measurement of experienced burnout", Journal of Organizational Behavior, 2(2), 1981, pp. 99-113.

[29] Maslach, C., W.B. Schaufeli, and M.P. Leiter, "Job Burnout", Annual Review of Psychology, 52(1), 2001, pp. 397-422.

[30] Moore, J.E., "One Road To Turnover: An Examination Of Work Exhaustion In Technology Professionals", MIS Quarterly, 24(1), 2000, pp. 141-168.

[31] Pearlin, L.I. and C. Schooler, "The Structure of Coping", Journal of Health and Social Behavior, 19(1), 1978, pp. 2-21.

[32] Pirkkalainen, H., M. Salo, M. Makkonen, and M. Tarafdar, "Coping with Technostress: When Emotional Responses Fail", Proceedings the 38th International Conference on Information Systems, 2017.

[33] Podsakoff, P.M., S.B. MacKenzie, Jeong-Yeon Lee, and N.P. Podsakoff, "Common Method Biases in Behavioral Research: A Critical Review of the Literature and Recommended Remedies", Journal of Applied Psychology, 88(5), 2003, p. 879.

[34] Ragu-Nathan, T.S., M. Tarafdar, B.S. Ragu-Nathan, and Q. Tu, "The Consequences of Technostress for End Users in Organizations: Conceptual Development and Empirical Validation", Information Systems Research, 19(4), 2008, pp. 417-433.

[35] Ringle, C.M., S. Wende, and J.-M. Becker, "Smartpls 3.", SmartPLS, 2015.

[36] Salo, M., H. Pirkkalainen, C. Chua, and T. Koskelainen, "Explaining Information Technology Users' Ways of Mitigating Technostress", European Conference of Information Systems - ECIS 2017, 2017.

[37] Skinner, E.A., K. Edge, J. Altman, and H. Sherwood, "Searching for the structure of coping: a review and critique of category systems for classifying ways of coping", Psychological Bulletin, 129(2), 2003, pp. 216-269.

[38] Srivastava, S.C., S. Chandra, and A. Shirish, "Technostress creators and job outcomes: theorising the moderating influence of personality traits", Information Systems Journal, 25(4), 2015, pp. 355-401.

[39] Stein, M.-K., S. Newell, E.L. Wagner, and R.D. Galliers, "Coping with information technology: Mixed emotions, vacillation, and nonconforming use patterns", MIS Quarterly, 39(2), 2015, p. 367. 
[40] Straub, D., M.-C. Boudreau, and D. Gefen, "Validation guidelines for is positivist research", Communications of the Association for Information Systems, 13, 2004, pp. 380-427.

[41] Tarafdar, M., C.L. Cooper, and J.-F. Stich, "The technostress trifecta - techno eustress, techno distress and design: Theoretical directions and an agenda for research", Information Systems Journal, 9(2), 2017, p. 204.

[42] Tarafdar, M., J. D'Arcy, O. Turel, and A. Gupta, "The Dark Side of Information Technology", MIT Sloan Management Review, 56(2), 2015, pp. 61-70.

[43] Tarafdar, M., Q. Tu, and T.S. Ragu-Nathan, "Impact of Technostress on End-User Satisfaction and Performance", Journal of Management Information Systems, 27(3), 2010, pp. 303-334.

[44] Turel, O., A. Serenko, and P. Giles, "Integrating Technology Addiction and Use: An Empirical Investigation of Online Auction Users", MIS Quarterly, 35(4), 2011, p. 1043 .

[45] Weinert, C., "Coping with discrepant information technology events: A literature review", Proceedings of the 27st European Conference of Information Systems - ECIS 2018,2018

[46] Weinert, C., S. Laumer, C. Maier, and T. Weitzel, "Is Information Technology Solely to Blame? The Influence of Work-home Conflict Dimensions on Work Exhaustion", ICIS 2016 Proceedings, 2016.

[47] Williams, L.J., J.R. Edwards, and R.J. Vandenberg, "Recent Advances in Causal Modeling Methods for Organizational and Management Research", Journal of Management, 29(6), 2003, p. 903

\section{Appendix}

\begin{tabular}{|c|c|c|}
\hline Constructs & Items & $\begin{array}{l}\text { Loa- } \\
\text { dings }\end{array}$ \\
\hline \multirow{3}{*}{ 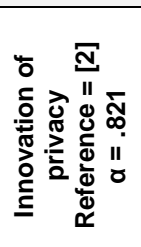 } & $\begin{array}{l}\text { I feel uncomfortable that my use of IT can be } \\
\text { easily monitored. }\end{array}$ & .884 \\
\hline & $\begin{array}{l}\text { I believe that my privacy can be compromised } \\
\text { because the activities with IT can be easily } \\
\text { tracked. }\end{array}$ & .932 \\
\hline & $\begin{array}{l}\text { I believe that the use of IT makes it easier to } \\
\text { invade my privacy. }\end{array}$ & .781 \\
\hline \multirow{4}{*}{ 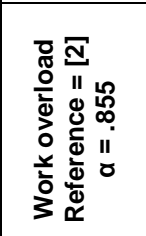 } & $\begin{array}{l}\text { I believe that the number of requests, problems or } \\
\text { complaints I deal with is more than expected. }\end{array}$ & .754 \\
\hline & $\begin{array}{l}\text { I believe that the amount of work I do interferes } \\
\text { with how well it is done. }\end{array}$ & .789 \\
\hline & I feel busy or rushed. & .890 \\
\hline & I feel pressured. & .906 \\
\hline \multirow{4}{*}{ 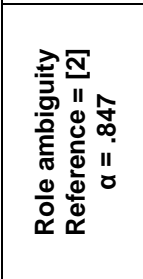 } & $\begin{array}{l}\text { I am unsure whether I have to deal with IT } \\
\text { problems or with my work activities. }\end{array}$ & .808 \\
\hline & $\begin{array}{l}\text { I am unsure what to prioritize: dealing with IT } \\
\text { problems or my work activities. }\end{array}$ & .829 \\
\hline & $\begin{array}{l}\text { can NOT allocate time properly for my work } \\
\text { activities because my time spent on IT-activities } \\
\text { varies. }\end{array}$ & .859 \\
\hline & $\begin{array}{l}\text { Time spent resolving IT problems takes time away } \\
\text { from fulfilling my work responsibilities. }\end{array}$ & .816 \\
\hline
\end{tabular}

\begin{tabular}{|c|c|c|}
\hline \multirow{3}{*}{ 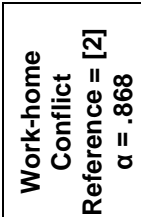 } & $\begin{array}{l}\text { Using IT blurs boundaries between my job and my } \\
\text { home life. }\end{array}$ & .879 \\
\hline & $\begin{array}{l}\text { Using IT for work-related responsibilities creates } \\
\text { conflicts with my home responsibilities. }\end{array}$ & .898 \\
\hline & $\begin{array}{l}\text { I do not get everything done at home because I } \\
\text { find myself completing job-related work due to IT. }\end{array}$ & .891 \\
\hline \multirow{3}{*}{ 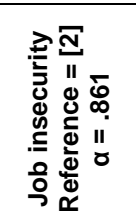 } & $\begin{array}{l}\text { IT will advance to an extent where my present job } \\
\text { can be performed by a less skilled individual. }\end{array}$ & .885 \\
\hline & $\begin{array}{l}\text { I am worried that new IT may pose a threat to my } \\
\text { job. }\end{array}$ & .846 \\
\hline & $\begin{array}{l}\text { I believe that IT make it easier for other people to } \\
\text { perform my work activities. }\end{array}$ & .922 \\
\hline \multirow{4}{*}{ 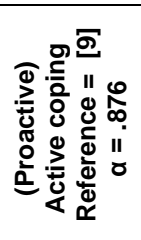 } & $\begin{array}{l}\text { I take additional action to try to get rid of the IT } \\
\text { problem. }\end{array}$ & .915 \\
\hline & $\begin{array}{l}\text { I concentrate my efforts in doing something about } \\
\text { the IT problem. }\end{array}$ & .892 \\
\hline & $\begin{array}{l}\text { I do at any time what needs to be done to get rid of } \\
\text { the IT problem. }\end{array}$ & .763 \\
\hline & I take direct action to get around the IT problem. & .829 \\
\hline \multirow{3}{*}{ 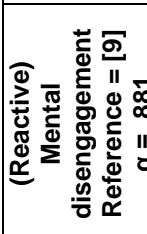 } & $\begin{array}{l}\text { I turn to work or other substitute activities to take } \\
\text { my mind off things. }\end{array}$ & .781 \\
\hline & $\begin{array}{l}\text { go to movies or watch TV, to think about it less. } \\
\text { I daydream about things other than this. }\end{array}$ & $\begin{array}{l}883 \\
.885 \\
\end{array}$ \\
\hline & & .858 \\
\hline \multirow{4}{*}{ 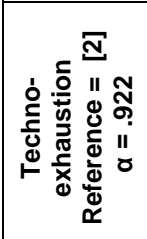 } & $\begin{array}{l}\text { I feel drained from activities that require me to use } \\
\text { IT. }\end{array}$ & .913 \\
\hline & I feel tired from my IT activities. & .934 \\
\hline & Working all day with ITs is a strain for me. & .839 \\
\hline & I feel burned out from my IT activities. & .912 \\
\hline
\end{tabular}

Table 3.

\section{Measurement items}

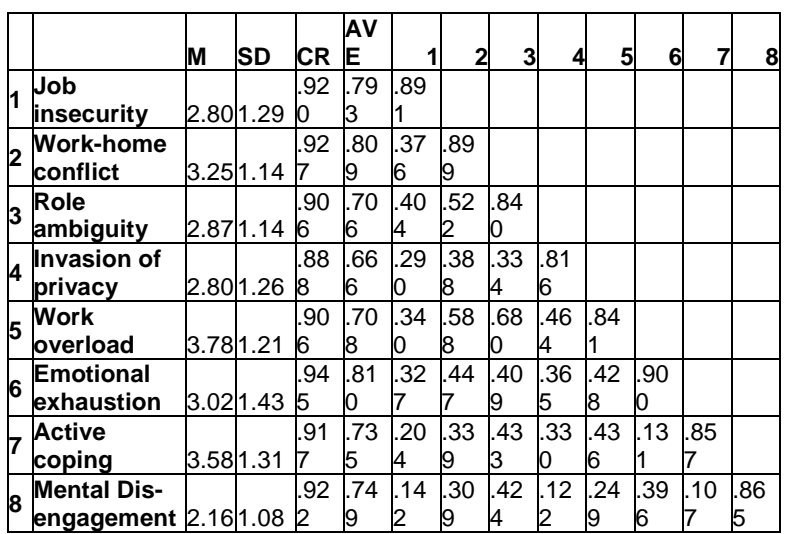

Table 4.

Measurement model of overall sample 